\title{
ATTITUDE AND OUTLOOK OF MEDICAL AND NON-MEDICAL STUDENTS TOWARDS BLOOD DONATION- A STUDY IN TELANGANA STATE
}

\author{
Naga Kalyani Pathuri ${ }^{1}$, Guvera Vasireddy², Desham Chelimela³, Ajay Mohan Varahala ${ }^{4}$ Ezhil Arasi Nagamuthu ${ }^{5}$
}

${ }^{1}$ Assistant Professor, Department of Pathology, Osmania Medical College and General Hospital, Hyderabad, Telangana, India. ${ }^{2}$ Assistant Professor, Department of Pathology, Osmania Medical College and General Hospital, Hyderabad, Telangana, India. 3 Senior Resident, Department of Community Medicine, Osmania Medical College and General Hospital, Hyderabad, Telangana, India. ${ }_{4}^{4}$ Associate Professor, Department of Paediatrics, Niloufer Hospital, Osmania Medical College, Hyderabad, Telangana, India. ${ }^{5}$ Retd. Professor and HOD, Department of Pathology, Osmania Medical College and General Hospital, Hyderabad, Telangana, India. ABSTRACT

\section{BACKGROUND}

There has been a tremendous advancement in the field of medicine over the past decade that revolutionised the treatment of serious illness and injuries and has increased the need for blood transfusion for patient's survival, to support them through recovery or to maintain their health. As per World Health Organisation (WHO) norms, regular blood donation by $1 \%$ of the population is the minimum requirement needed to meet the country's most basic requirements. Ironically, in a populous country like India the unavailability of blood has not only led to many patients suffering from ill-health but also to deaths.

Aims and Objectives- The present study aims at determining the attitude and awareness among the medical and non-medical students regarding blood donation and blood banking services.

\section{MATERIALS AND METHODS}

This is a cross-sectional study based on a preformed and pretested questionnaire covering the domains of attitude and knowledge the students have regarding blood donation and blood banking practices. Equal number of Medical and Engineering students participated in the survey. The entire data was analysed using Epi Info Version 7.2.1.0 software by CDC. Frequency tables were drawn and $P$ values for necessary aspects were calculated using Chi-square tests.

\section{RESULTS}

A total of 700 students participated in the survey. Age of the students ranged from 18 to 21 years. Among the respondents $52 \%$ came to know about blood donation through media, 32\% through friends and 10\% through teachers at school and only less than $5 \%$ through family. $62 \%$ of the respondents feel that publicity regarding the importance of blood donation is not adequate. In the present study, $89.5 \%$ of medical and $95 \%$ of the Engineering students have not donated blood till date. $23 \%$ of the medical students and $22.56 \%$ of the engineering students had a negative attitude towards blood donation. The knowledge the medical students had on various aspects of blood banking practices is also very limited.

\section{CONCLUSION}

Similar studies have to be taken up across the state of Telangana to get a larger picture of the socially relevant issue of blood donation. If the results are comparable to the present study, then interventional and rectification measures have to be taken up on a war footing.

\section{KEY WORDS}

Attitude, Media, Medicos, Outlook, Telangana State, Voluntary Blood Donation.

HOW TO CITE THIS ARTICLE: Pathuri NK, Vasireddy G, Chelimela D, et al. Attitude and outlook of medical and non-medical students towards blood donation- a study in Telangana state. J. Evolution Med. Dent. Sci. 2018;7(25):2944-2948, DOI: $10.14260 /$ jemds/2018/663

\section{BACKGROUND}

There has been a tremendous advancement in the field of medicine over the past decade that has revolutionised the treatment of serious illness and injuries, and has increased the need for blood transfusion for patient's survival, to support them through recovery or to maintain their health.(1)

'Financial or Other Competing Interest': None.

Submission 11-05-2018, Peer Review 03-06-2018,

Acceptance 09-06-2018, Published 18-06-2018.

Corresponding Author:

Dr. Guvera Vasireddy,

\#20304, Willow Block,

Indu Fortune Gardenia Apartments,

Hyderabad-500072,

Telangana, India.

E-mail: guvera@gmail.com

DOI: $10.14260 /$ jemds $/ 2018 / 663$

\section{(c) $(1)(5)$}

Artificial blood and its usage in regular medical practice is still a farfetched dream. Until such time human blood collected through voluntary blood donation is the only source of blood and its components. As per World Health Organization (WHO) norms, regular donation by $1 \%$ of the population is the minimum needed to meet the country's most basic requirements for blood. Ironically, in a country like India, which today is standing $2^{\text {nd }}$ in the world population and is estimated to top the list by 2050 , there is a perennial deficit of blood and its components. The need for blood transfusion may arise at any time in both urban and rural areas. The unavailability of blood has led to deaths of many patients requiring transfusion.

\section{Need for the Study}

Literature search revealed no statistics and no studies conducted on the attitude and awareness of medical students 
regarding blood donation and blood banking services in the newly formed State of Telangana or in the erstwhile Andhra Pradesh. Hence, the present study which is the first of its kind in the Telangana State.

\section{Objective}

Youth and more specifically students form the major chunk of eligible blood donors in any geographical area. Our study aims at determining the attitude, outlook and awareness the medical and non-medical students have towards blood donation and blood banking services.

\section{MATERIALS AND METHODS}

This study is a cross-sectional study based on a preformed and pretested questionnaire. In a pilot study conducted among 40 medical students, awareness and knowledge regarding blood donation was $30 \%$. (As per pilot study, students were considered aware of blood donation if all the three following questions were answered correctly: 1 . Minimum eligible age for blood donation, 2. Minimum haemoglobin percentage for blood donation and 3. Infections transmitted through blood transfusion) with $95 \%$ confidence interval using the formula $n=z^{\wedge} 2^{*} p^{*} q / l^{\wedge} 2$, the sample size was determined as 336. Adding 5\% non-response rate, sample was rounded off to 350.350 students each from one medical and one engineering college were taken into study for comparing the results. Convenience sampling was done in selecting the colleges, as they were easily accessible. All students whoever were present and free at the time of data collection in the college were included in the study. All the participants were briefed about the objective of this study and were assured confidentiality to get genuine answers. The structured survey was conducted using a Questionnaire comprising of thirty questions, which covered the domains of attitude and knowledge the students have regarding blood donation and blood banking practices. Medical students were from Osmania Medical College, Hyderabad and Engineering students from ACE Engineering College, Ghatkesar Mandal, Medchal District. The entire data was analysed using Epi Info software Version 7.2.1.0 developed by CDC. Frequency tables were drawn and $P$ values for necessary aspects were calculated using Chi-square tests.

\section{RESULTS}

A total of 700 students participated in the survey, of which 350 were medical students from $2^{\text {nd }}$ and $3^{\text {rd }}$ year MBBS studying at Osmania Medical College, Hyderabad, TS which is one of the renowned Government Medical Colleges in the country and 350 students were $1^{\text {st }}$ and $2^{\text {nd }}$ year Engineering students from ACE Engineering College, Ghatkesar Mandal which is a suburb of Hyderabad city. 19 of the engineering college students were excluded, as they were $<18$ years old. Age of the students ranged from 18 to 21 years.

\section{Attitude and Outlook}

Among the respondents $52 \%$ came to know about blood donation through media, $32 \%$ through friends, $10 \%$ through teachers at school and only $<5 \%$ through family.

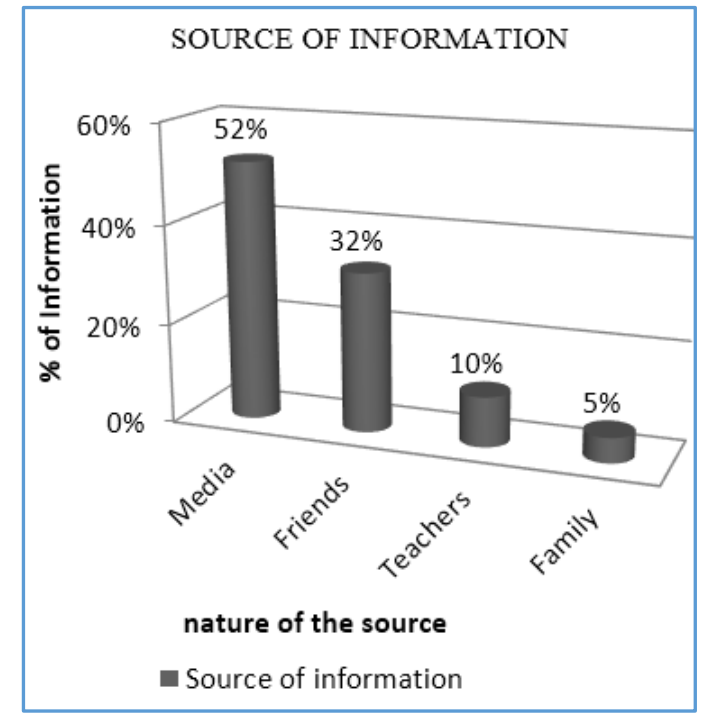

Figure 1

$62 \%$ of the respondents feel that publicity regarding the importance of blood donation is not adequate.

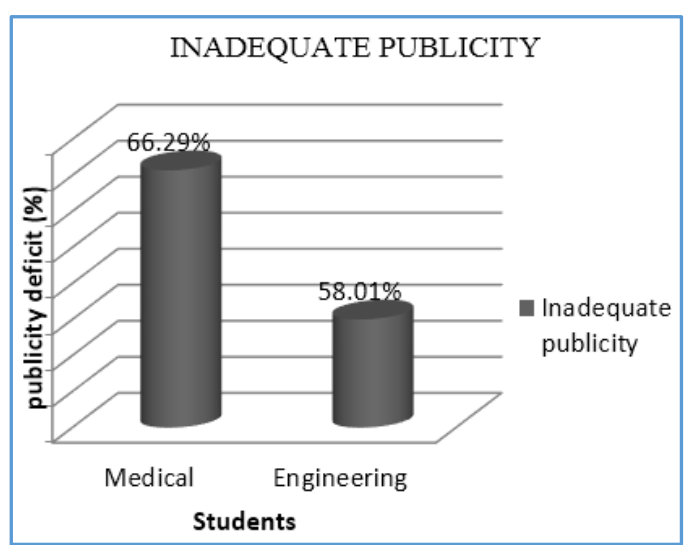

Figure 2

Only $12.75 \%$ of the students belonging to a Government Medical College prefer to procure or donate blood at their own or any other government facility as opposed to $68.27 \%$ of the medicos who preferred a private or charitable trust blood bank for the same. Similarly, only $14.80 \%$ of engineering students as opposed to $59.82 \%$ preferred a government blood bank.

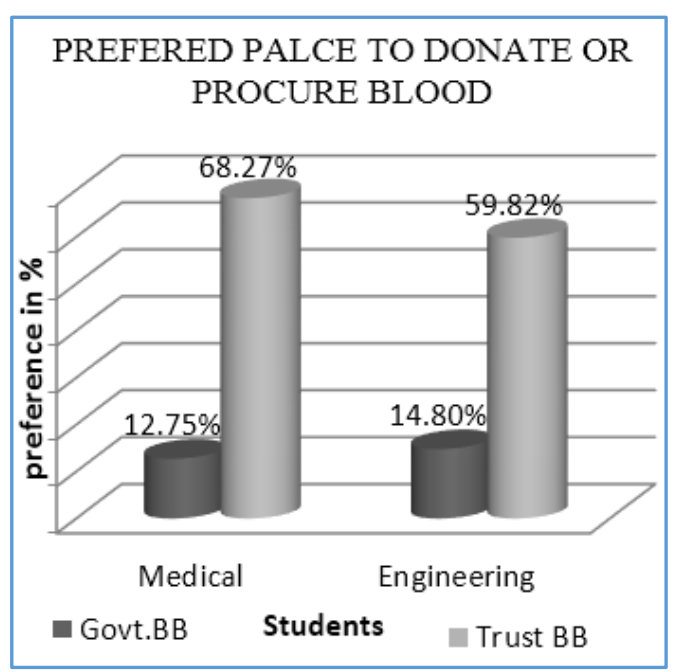

Figure 3 


\section{Practice}

In the present study, of the total 681 eligible aged donors (700 minus 19) $89.5 \%$ of medical and $95 \%$ of the Engineering students have not donated blood till date. $23 \%$ of the medical students had negative reasons like blood donation leads to weakness, infections etc. $18.5 \%$ of them were not aware of the importance of blood donation and $48 \%$ had no specific reason for not donating. Amongst the engineering students, $22.56 \%$ of students had a negative attitude towards blood donation and $49.5 \%$ of them were not aware of the importance of the blood donation.

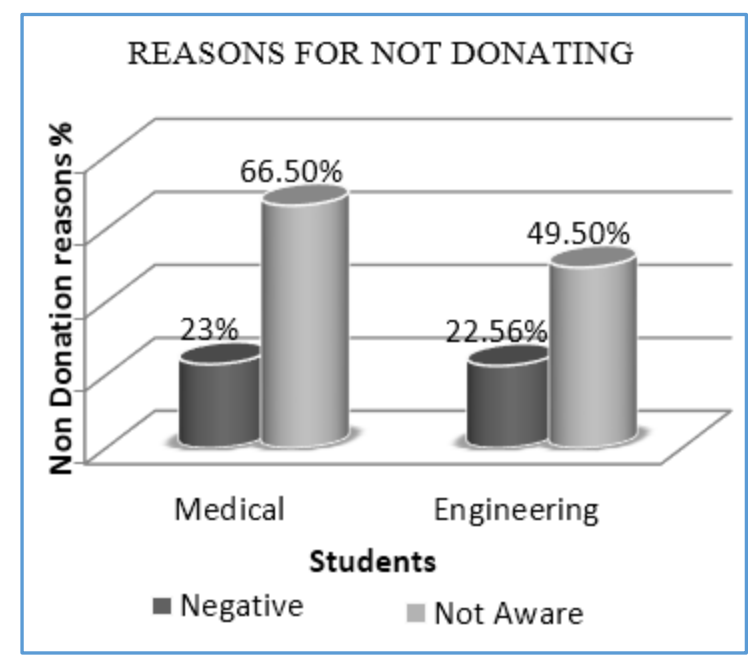

Figure 4

\section{Awareness and Knowledge}

$70.54 \%$ of the medical and $59 \%$ of the non-medical students do not know about the percentage of eligible population that donates blood in India. $92.9 \%$ of medical and $85 \%$ of nonmedical students are not aware of the approximate annual requirement of blood units/ year for the city of Hyderabad.

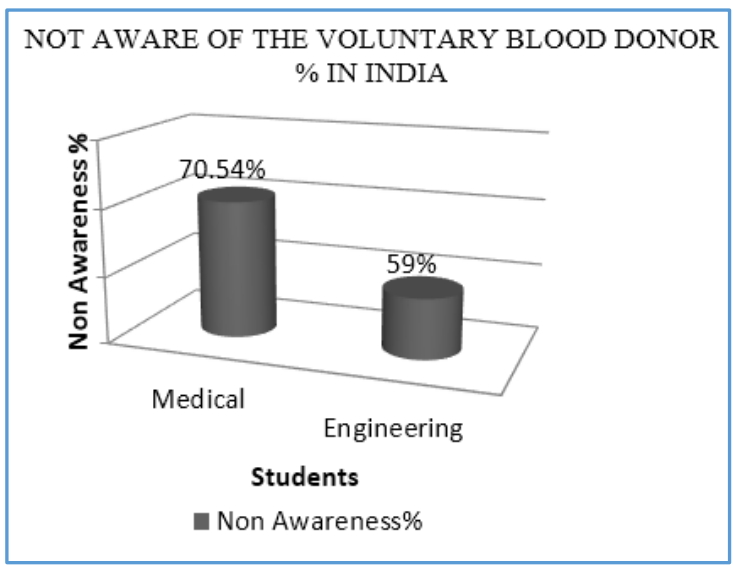

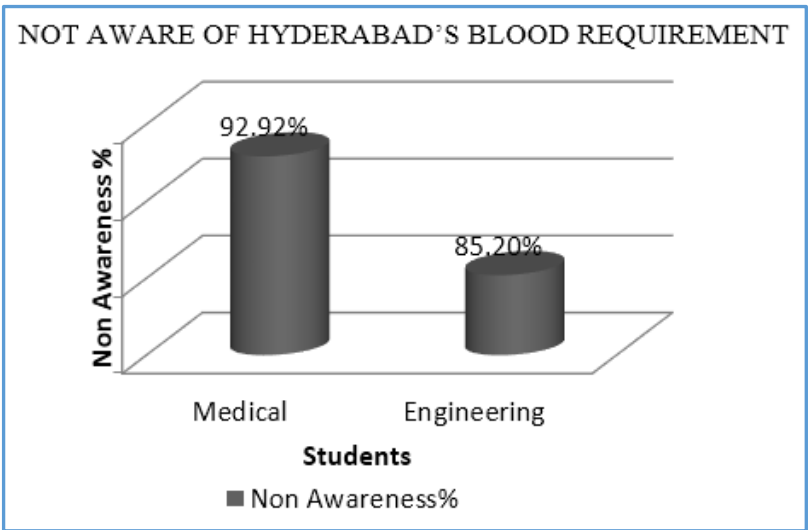

\section{Figure 6}

Only $21.25 \%$ of the $2^{\text {nd }}$ and $3^{\text {rd }}$ year medical students had knowledge about the minimum haemoglobin \% required to donate blood. Similarly, only $12.39 \%$ of the engineering students were aware about the $\mathrm{Hb} \%$ criteria to be called an eligible donor.

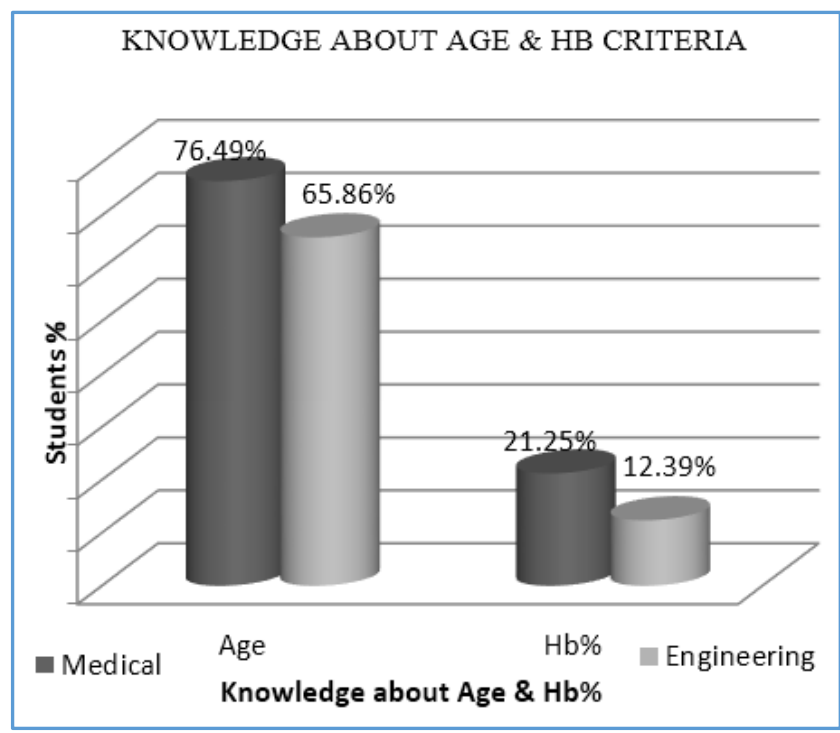

Figure 7

The detailed results of the knowledge the medical students have on various aspects of blood banking practices are as follows: Only $24 \%$ of the students knew the correct volume of blood collected during every donation. 54\% of the students had no idea as to what is to be done with a blood bag that is tested positive for any transfusion transmitted infection. $68 \%$ of the students were not aware of the shelf life of the whole blood and $97 \%$ did not know the storage temperature of the platelets.

Figure 5

\begin{tabular}{|c|c|}
\hline Question & Percentage (Correct Response) \\
\hline The minimum eligible Haemoglobin \% for blood donation is (18 yrs.) & $21.25 \%$ \\
\hline Blood volume collected during every donation is (350/450 mL) & $24.08 \%$ \\
\hline $\begin{array}{c}\text { Name three infections that can be transmitted through blood transfusion } \\
\text { (HIV, Hep B and C, Malaria, Syphilis) }\end{array}$ & $53.54 \%$ \\
\hline The three components that can be prepared from a "Triple Bag” (PC, FFP, Platelets) & $39.94 \%$ \\
\hline Storage temperature of platelets is (22 ${ }^{\circ} \mathrm{c}$ ) & $3.83 \%$ \\
\hline Shelf Life (Expiry Date) of whole blood when stored at 2 - 60 $\mathrm{C}$ is (35 days) & $32.58 \%$ \\
\hline Table 1. Knowledge of Medical Students on various aspects of Blood Banking Practices
\end{tabular}




\begin{tabular}{|c|c|c|c|c|}
\hline Q. No. & Knowledge Regarding & $\begin{array}{c}\text { Frequency of Medical Students } \\
\text { who were Aware n ( 350) }\end{array}$ & $\begin{array}{c}\text { Frequency of Engineering } \\
\text { Students who were Aware n (331) }\end{array}$ & $\begin{array}{c}\text { OR and P } \\
\text { Value }\end{array}$ \\
\hline Q1 & $\begin{array}{c}\text { Minimum eligible age for blood } \\
\text { donation }\end{array}$ & $270(77.0 \%)$ & $218(65.8 \%)$ & $\begin{array}{c}0 R: 1.2-2.3 \\
\text { P<0.05 }\end{array}$ \\
\hline Q2 & $\begin{array}{c}\text { Infections transmitted through } \\
\text { blood transfusion }\end{array}$ & $189(54.0 \%)$ & $11(3.32 \%)$ & $\begin{array}{c}\text { OR: } 18-66 \\
\text { P<0.05 }\end{array}$ \\
\hline Q3 & Universal blood donor & $282(80.5 \%)$ & $12(3.62 \%)$ & $\begin{array}{c}0 R: 57-204 \\
\text { P<0.05 }\end{array}$ \\
\hline \multicolumn{2}{|c|}{ Table 2. Comparison Table with P values regarding Knowledge of Medical and Non-Medical Students } \\
\hline
\end{tabular}

*Note: For Q1- 18 yrs.; For Q2- HIV, Hepatitis B, malaria and/ or Syphilis; For Q3- O group or O+ were scored as correct answers.

\section{DISCUSSION}

Of the 112.5 million blood donations collected globally, approximately half are collected in high-income countries, home to only $19 \%$ of the world's population. ${ }^{1}$

The shortage of blood units in India was estimated at 1.1 million units- as blood is measured with a unit being either $350 \mathrm{~mL}$ or $450 \mathrm{~mL}$ in 2015 - 16, Minister for Health and Family Welfare, JP Nadda told the Lok Sabha in July 2016. In terms of percentage India is $9 \%$ short of its needs- the shortage reducing from $17 \%$ in 2013 - 2014. ${ }^{2}$ This unfortunate situation has arisen due to the lack of awareness about the importance of blood donation. Voluntary, nonremunerated donors from low-risk populations form the cornerstone of safe and adequate blood supply. Yet, voluntary donation comprises only about 70 percent of the demand in India with the rest being met by replacement donation.

Today, the requirement for blood in Hyderabad alone has gone up to 2.5 lakh units per year. One of the main reasons for this is Hyderabad becoming a medical tourism hub. ${ }^{3}$ Published data so far shows that there are no such studies in the state of Telangana or United Andhra Pradesh previously to understand the awareness and outlook of medical and nonmedical students, who form the potential donor community. We have made some interesting observations in our study. The domains we tested broadly fell under attitude/ outlook, practice and knowledge/ awareness.

Majority of students have come to know about blood donation only through media and friends followed by school teachers. Majority of the children reaching the age of 18 or who have crossed 18 years continue to live with their parents and extended families in India. According to WHO statistics, one in every 3 persons will need a blood transfusion during their lifetime. Despite these families are failing to educate their children regarding the importance of blood donation. Family played a menial role in educating and encouraging the children to become tomorrow's donor when they reach the age of eligibility.

The students are unaware of the country's and more specifically city's blood requirements due to which they never felt the necessity to walk up to a camp or blood bank to donate blood. As a matter of fact only very few medical students had knowledge regarding annual blood requirement of Hyderabad, India. They also strongly feel that the publicity regarding blood donation is grossly inadequate.

Most of the students (88\%) have not donated blood so far either due to lack of information regarding the importance of blood donation or due to certain misconceptions, which is almost comparable with studies among health professional students by Sunetra Sharma et al (92\%), ${ }^{4}$ Manikandan $S$ et al $(89.25 \%)^{5}$ and by Desai KN et al (78.7\%). ${ }^{6}$ In our study, the issue of concern is that the medical students themselves have a lot of misconceptions about blood donation. Most of the engineering students (59.82\%) recommended a charitable or trust blood bank to donate or procure blood. Ironically being from a Government Medical College, only $12.75 \%$ of the medicos recommended a government blood bank for donation and procurement of blood which is less than that of the engineering student's preference (14.80\%). Almost $68.27 \%$ of medicos preferred a charitable trust blood bank. This issue has to be viewed rather seriously, as the medical students do not have enough faith in the government blood banks and their services.

In the present study, only $21 \%$ of the medicos knew correctly about the minimum haemoglobin percentage required to donate blood. This result is comparable to the result of study conducted by Singh et al, ${ }^{7}$ where only $22 \%$ of the junior doctors were aware of the required haemoglobin percentage. The medicos also had very limited knowledge about various common aspects of blood banking like the shelf life of whole blood, temperature of storage of platelets, components etc. The analyses of various aspects of our study reveals that most of the eligible youth are ignorant about the blood needs of the society they live in. Most of the medical students also lack basic knowledge of blood banking services.

However, compared to engineering students, medical students had more knowledge regarding minimum eligible age for blood donation, infections transmitted through blood donation and knowledge about Universal blood donor $(\mathrm{p}<0.05)$. But when stand-alone statistics are studied, the awareness and knowledge medicos had is very limited and disappointing.

\section{CONCLUSION}

Similar studies have to be taken up by the medical faculty across the state to get a larger picture of the socially relevant issue of blood donation. If the results are comparable to the present study, then strong recommendations need to be made by the expert team to the State Government and NACO (Telangana State AIDS Control Society) to double up the publicity campaigns on blood donation.

Once a medical student passes his 1 st MBBS and starts his/ her clinical postings, it is presumed that the medico automatically learns about blood banking. But not having taught them specifically about blood donation, its requirements and importance, seem to increase the cost of blood banking services. Hence, the idea of including a chapter on "Blood donation and blood banking" in the MBBS curriculum also has to be revisited by expert team. 


\section{Jemds.com}

The importance of Blood Donation and Blood Banking Services has to be impressed upon by the faculty as a socially relevant issue. The topic of "Blood needs of the society and importance of blood donation" has to be incorporated into the induction training given to the freshers both in medical and engineering colleges.

An issue of such magnitude can be addressed only when the entire society marches forward together. If this happens, it would not take too long for the state of Telangana to achieve the target of $100 \%$ voluntary blood donation.

\section{ACKNOWLEDGEMENTS}

I sincerely thank the Management, Principal, Faculty and Students of ACE Engineering College, Ghatkesar Mandal who extended their cooperation and permitted me to conduct the survey. I also thank the students of 2014 and 2015 batch MBBS students of Osmania Medical College who participated in the survey to make this study possible.

\section{REFERENCES}

[1] WHO Library Cataloguing-in-Publication Data: Towards $100 \%$ voluntary blood donation: a global framework for action. World Health Organization 2010.

\section{Original Research Article}

[2] Government Of India Ministry Of Health And Family Welfare Department of Health And Family Welfare Lok Sabha Unstarred Question No. 2282 To Be Answered On 29th July, 2016 Blood Banks. http://164.100.47.190/loksabhaquestions/annex/9/ AU2282.pdf

[3] https://timesofindia.indiatimes.com/city/hyderabad/ hyderabad-requires-2-5-lakh-units-of-blood-everyyear-have-you-donated-yet/articleshow/59129081.

[4] Sarma S, Suresh Roy L. Awareness about blood donation among medical students in Manipur Sch J App Med Sci 2016;4(3E):994-6.

[5] Manikandan S, Srikumar R, Ruvanthika PN. A study on knowledge, attitude and practice on blood donation among health professional students in Chennai, Tamil Nadu, South India. Int J Sci Res Pub 2013;3(3):1-4.

[6] Desai KN, Satapara V. A study on knowledge, attitude, and practice on blood donation among health professional students in Anand: Gujarat. J Applied Hematol 2014;5(2):51-3.

[7] Singh A, Singh N, Singh P, et al. A study on awareness about blood donation and blood transfusion among junior doctors in teaching hospitals of Meerut. International Journal of Contemporary Medical Research 2016;3(6):1851-3. 